Trinity University

Digital Commons @ Trinity

Modern Languages and Literatures Faculty

Research

Modern Languages and Literatures Department

2018

\title{
El abrazo de la serpiente o la re-escritura del Amazonas dentro de una ética ecológica y poscolonial
}

Ana María Mutis

Trinity University, amutis@trinity.edu

Follow this and additional works at: https://digitalcommons.trinity.edu/mll_faculty

Part of the Modern Languages Commons

\section{Repository Citation}

Mutis, A. M. (2018). El abrazo de la serpiente o la re-escritura del Amazonas dentro de una ética ecológica y poscolonial. Hispanic Research Journal: Iberian and Latin American Studies, 19(1), 29-40. http://doi.org/10.1080/14682737.2018.1418990

This Article is brought to you for free and open access by the Modern Languages and Literatures Department at Digital Commons @ Trinity. It has been accepted for inclusion in Modern Languages and Literatures Faculty Research by an authorized administrator of Digital Commons @ Trinity. For more information, please contact jcostanz@trinity.edu. 


\title{
El abrazo de la serpiente o la re-escritura del Amazonas dentro de una ética ecológica y poscolonial
}

\author{
Ana María Mutis \\ Trinity University, San Antonio, TX, USA
}

\begin{abstract}
RESUMEN
A primera vista la película colombiana El abrazo de la serpiente (2015) trata del encuentro de dos culturas y dos visiones divergentes del mundo: la de los indígenas del Amazonas y la de los científicos extranjeros que exploraron la región durante la primera mitad del siglo XX. El presente estudio propone que la película de Ciro Guerra es también una obra sobre cómo escribir sobre el Amazonas. Así lo demuestra el andamiaje metaficticio de la película que, a partir de la revisión y refiguración de los textos científicos que la inspiraron, simula la construcción de un documento que se adhiere a una ética ecológica poscolonial. Mediante el análisis de los elementos autoreflexivos de la película a la luz de la ecocrítica poscolonial, este trabajo explora la manera novedosa en que la agenda ecológica y poscolonial de la película está inscrita dentro de una lógica posmoderna que revela y corrige la opresión colonial escondida en el discurso hegemónico.
\end{abstract}

\begin{abstract}
At first glance the Colombian film El abrazo de la serpiente (2015) is about the encounter of two cultures with two divergent visions of the world: the indigenous people of the Amazon and the foreign scientists who explored the region during the first half of the twentieth century. This study proposes that Ciro Guerra's film is also a commentary on how to write about the Amazon. This is supported by the metafictional strategies deployed by the film which, based on the revision and refiguration of the scientific texts that inspired it, simulates the construction of a document that adheres to a postcolonial ecological ethics. Through the analysis of the film's self-reflexive elements in the light of postcolonial ecocriticism, this article explores the novel ways in which the film's ecological and postcolonial agenda is inscribed within a postmodern logic that reveals and corrects colonial oppression concealed in hegemonic discourse.
\end{abstract}

\section{PALABRAS CLAVE}

Amazonas; cine; ecocrítica poscolonial; posmodernismo; El abrazo de la serpiente

\section{KEYWORDS}

Amazon; film; postcolonial ecocriticism; postmodernism; El abrazo de la serpiente

La película El abrazo de la serpiente (2015) esboza en su título la imagen del reptil que se desplaza formando un espiral, que se desliza lenta y ondulante, envolviendo por medio de círculos consecutivos a su presa. El título, sabemos cerca del final de la película, refiere al viaje espiritual bajo los efectos alucinógenos de la planta Yakruna, en el que el abrazo de una

CONTACT Ana María Mutis amutis@trinity.edu @ Department of Modern Languages and Literatures, Trinity University, One Trinity Place, San Antonio, TX 78212, USA. 
serpiente transporta al que la consume a lugares antiguos y le revela verdades ocultas. Pero también refiere al formato narrativo de la película que enlaza las historias de dos viajes, de dos encuentros, siguiendo una trayectoria marcada por la circularidad y la repetición. Por medio de tomas del río que conectan las dos etapas de la historia, la película entreteje el viaje de Karamakate - el último sobreviviente de su tribu amazónica - y el explorador alemán Theo Von Martius en busca de la Yakruna, con su travesía años después en compañía del científico americano Richard Evans Schultes con el mismo propósito. El sinuoso trazado del río que enrama los dos viajes reproduce la imagen que nos ofrece el título de la serpiente enroscándose para formar un abrazo, por lo que ya el título descubre, si bien de manera furtiva, el andamiaje narrativo de la película.

Este gesto autoconsciente no es el único ni el más evidente. El abrazo - nombre con el que me referiré a la película de ahora en adelante - despliega diversas estrategias autorreferenciales que ponen de relieve su condición de artefacto, de fabricación creativa. El presente trabajo propone que la urdimbre metaficticia de la película busca simular la construcción de un documento, o mejor, la recuperación de varios documentos sobre el Amazonas en uno que representa a la región y a su gente dentro de una ética ecológica poscolonial. Al poner al descubierto su condición de documento, la película denota una orientación postmoderna que, preocupada por el plano discursivo, cuestiona los discursos tradicionales sobre las comunidades amazónicas y los refigura dentro de parámetros de justicia social y ambiental. De este modo El abrazo se erige como una película sobre la construcción ética de historias sobre el Amazonas y su gente, sobre la necesaria colaboración de diferentes culturas en la elaboración de estas historias, y sobre el poder de estos relatos de transformar la realidad social y ecológica de la región.

Antes de entrar a analizar el andamiaje metaficticio de la película y el mensaje ecológico poscolonial que tras él se esconde, es importante advertir que al vincular el posmodernismo con la ecocrítica el presente estudio se enfrenta a un debate en materia teórica. Como observa Serpil Oppermann (2006), la ecocrítica ha sido renuente a aceptar acercamientos postmodernistas a su objeto de estudio y la principal razón de este rechazo es la creencia de que el énfasis en la construcción del relato, en la forma y estructura narrativa, marginan al mundo natural. En particular la metaficción ha sido acusada de ser una escritura narcisista que ignora la realidad a favor de una exploración minuciosa de sí misma (Waugh 2013, 9), percepción a la que muchos ecocríticos se adhieren. Lawrence Buell, en su llamado a revivir la representación de la naturaleza en el arte, critica duramente la teoría literaria que ha privilegiado el estudio de la forma y ha dejado al margen la dimensión referencial de la literatura $(1996,86)$. De similar parecer son Terry Gifford y Laurence Coupe quienes, como asegura Oppermann, promueven el estudio de la naturaleza en la literatura desde una perspectiva referencial fundada en el realismo $(2006,111)$. Como bien expone Oppermann, esta orientación realista, además de ser limitante, descuida el aporte que un postmodernismo ecocrítico puede ofrecer en el análisis de obras que, como El abrazo, abordan la problemática ambiental a partir de una preocupación por la manera en que ésta se representa a nivel discursivo e indagan acerca de las implicaciones que dichas representaciones tienen en la valoración del medio ambiente. Como se demostrará a continuación, El abrazo da sustento a la afirmación de Oppermann de que una ficción posmoderna puede incorporar una agenda ecológica al postularse como una película sobre cómo escribir el Amazonas y cómo documentar las historias de sus pueblos y su naturaleza dentro de una ética social y ambiental. La película da forma artística a la aspiración de la ecocrítica poscolonial, que 
es, según Graham Huggan y Helen Tiffin, 'to make exploitation and discrimination of all kinds, both human and non-human, visible in the world; and, in so doing, to help make them obsolete' $(2015,16)$ y lo hace, no solamente denunciando estos actos, sino revelando y corrigiendo la opresión colonial que se esconde en el discurso hegemónico.

Un aspecto de la película que ilustra su lógica posmoderna es su cercanía, tanto en la forma como en el contenido, con los documentos que la inspiraron. El abrazo está basada en el libro Dos años entre los indios: viajes por el noroeste brasileño, 1903-1905 de Theodor Koch-Grünberg ([1909-1910] 1995) y en la biografía One River de Wade Davis (1996) que relata las exploraciones de Richard Evan Schultes en el Amazonas colombiano desde 1941 hasta 1953, así como en los diarios y fotografías de Schultes. Los textos y el material fotográfico de estas obras inspiraron, además del contenido de la película, su identidad estética que, como dice su cinematógrafo David Gallego (2016,18-19), 'está guiada por estas fotografías, sus marcados contrastes, la granulación de las imágenes, su falta de definición'. Añade Gallego que el director Ciro Guerra eligió filmar en blanco y negro para replicar las imágenes de un documento oculto que iba a revelar un secreto y recrear una realidad que ya no existe más pues ha sido destruida por el hombre occidental (18).

Estos dos propósitos - el de certificar el sustrato documental de la película y el de imprimirle un tono elegíaco - se consiguen mediante un tratamiento fotográfico que, al adoptar la estética de las fotografías en blanco y negro, aprovecha las asociaciones de la fotografía con la realidad y con la muerte. En On Photography Susan Sontag establece que el vínculo de la fotografía con la realidad está en que la foto ofrece una evidencia, una prueba irrefutable de que lo fotografiado ocurrió $(1977,5)$. Es evidencia también del paso del tiempo, del envejecimiento de los sujetos fotografiados, por lo que Sontag concluye que hay un vínculo entre la fotografía y la muerte, manifiesto en el hecho de que las fotos de personas exponen la vulnerabilidad de las vidas que se dirigen hacia su propia destrucción (70). De manera parecida Roland Barthes encuentra el poder testimonial de la fotografía en que ésta constituye un certificado de autenticidad: 'I can never deny that the thing has been there' $(1993,76)$. La facultad de la fotografía de resucitar el pasado y dar testimonio del paso del tiempo, nos recuerda nuestra propia mortalidad. Pero para Barthes, los vínculos más claros de la fotografía con la muerte están en la transformación del sujeto fotografiado en objeto, en una imagen total, que personifica a la muerte (14). Por su parte John Berger encuentra la asociación de la fotografía con la muerte en su facultad de detener el tiempo: 'photography, because it stops the flow of life, is always flirting with death' $(1993,122)$. El tratamiento estético de El abrazo apela a estos atributos de la fotografía con el doble propósito de mostrarse como un documento veraz y a la vez transmitir un sentimiento nostálgico.

Ambos propósitos contribuyen al afán de la película de concientizar al público sobre la necesidad de preservar el territorio Amazónico y proteger a sus comunidades, reafirmando con ello la impronta ecológica y poscolonial del filme. La alusión a la muerte como mecanismo de denuncia o de advertencia resulta problemática para Angelo Muredda, quien cuestiona el contenido poscolonial de El abrazo en tanto que cae sin quererlo en ciertos prejuicios colonialistas como el del uso del 'vanishing native trope' $(2016,75)$. El cliché del indígena cuya desaparición es una consecuencia inevitable del progreso ha servido, como explica Johanna Feier, para justificar las acciones de los responsables de su exterminio (2011, 12-13). Muredda critica el uso de este recurso que en su opinión 'buries deeper the people it intends to resurrect' $(2016,75)$. Si bien es cierto que el mito de la muerte del 
indígena ha servido para reducirlo a un elemento del pasado, en El abrazo la repetición y la duplicación inscriben el tiempo dentro de un formato circular que rechaza la caducidad del pasado. El viaje que se repite, los lugares y las personas que se duplican, los diálogos que espejean otras conversaciones, crean la idea de un ciclo infinito que atenúa el carácter final de la muerte. Igualmente, esta circularidad, en especial la circularidad temporal, es un rechazo a la temporalidad lineal de las narrativas de progreso utilizadas por el discurso colonial. En una subversión más del modelo colonial del progreso, del cual el río es un tropo frecuente, el río de El abrazo no avanza sino que recorre los mismos lugares, como si sus aguas fluyeran en círculos emulando el abrazo de la serpiente.

Pero aún si quedan rezagos de algún prejuicio colonialista en la película, éstos palidecen frente a la contundencia de su mensaje anticolonial, que de manera explícita y directa denuncia los abusos de las comunidades religiosas y las empresas caucheras en la región. Los peligros y desafíos que amenazaban y aún hoy día acechan a las comunidades del Amazonas, como son la muerte, el despojo, la explotación, la destrucción de su hábitat y la aculturación, son presentados sin miramientos en la película de Guerra. Más significativo aún es el hecho de que la película inserta al indígena como actor principal de la narrativa del Amazonas, le da una voz que antes le había sido negada, y lo hace sin homogenizar a las comunidades indígenas pues incluye sus diferentes perspectivas, costumbres y lenguas.

Es importante notar que la inserción de la voz del indígena se acompaña de una variedad de estrategias autoreflexivas que llaman la atención al hecho de que la película es un documento ensamblado a partir de otros documentos. Además de la estética fotográfica que señala la naturaleza documental del filme, también son elementos autoreflexivos los libros y fotografías presentes físicamente en la película que funcionan como repeticiones de partes de la historia contada. Este tipo de desdoblamiento puede apreciarse claramente en la escena en que Karamakate ve que Schultes tiene en su poder el libro Zwei Jahre unter den Indianern (Dos años entre los indios) de Theodor Koch-Grünberg. Aquí el libro es la obra de Theo von Martius con quien Karamakate realiza su primer viaje. El propio von Martius es producto de una duplicación, pues es un personaje ficticio inspirado en Koch-Grünberg, pero recibe el apellido de otro explorador, Karl Friedrich Phillip von Martius, quien viajó por el norte del Amazonas en 1821. La genealogía de exploradores contenida en la figura de von Martius enfatiza el tema de la repetición, que se despliega de forma metaficticia en el libro que lleva Schultes. En la portada del libro aparece dibujada la imagen de un indígena que nos recuerda a Karamakate en su juventud, hecho que el protagonista parece pasar por alto. Sin embargo, así como Don Quijote y Sancho Panza aprenden que ellos son los protagonistas de un libro, Karamakate se enfrenta a su doble realidad al tomar en sus manos el libro de Theo. Karamakate no tarda en reconocer la duplicación causada por las fotografías del libro, duplicación que él inscribe dentro de la mitología del Chullachaqui, que consiste en la creencia amazónica de que toda persona tiene un doble que es una imagen vacía de sí mismo. Pero la duplicidad proviene también del libro, que actúa como un espejo que lo desdobla a él y a otros protagonistas de la película en personajes de un texto (Figura 1).

En este sentido el libro actúa como una mise en abyme, o un espejo dentro del relato, que presenta una versión en miniatura de la historia que se está contando en la película, desdibujando las fronteras entre lo real y lo fabricado. El término mise en abyme, acuñado por André Gide en 1898, designa la duplicación interna de una obra obtenida al insertar una segunda representación de la obra dentro del original $(2000,30)$. Lucien Dällenbach parte de la definición de Gide para elaborar una tipología de este recurso metaficticio, el 


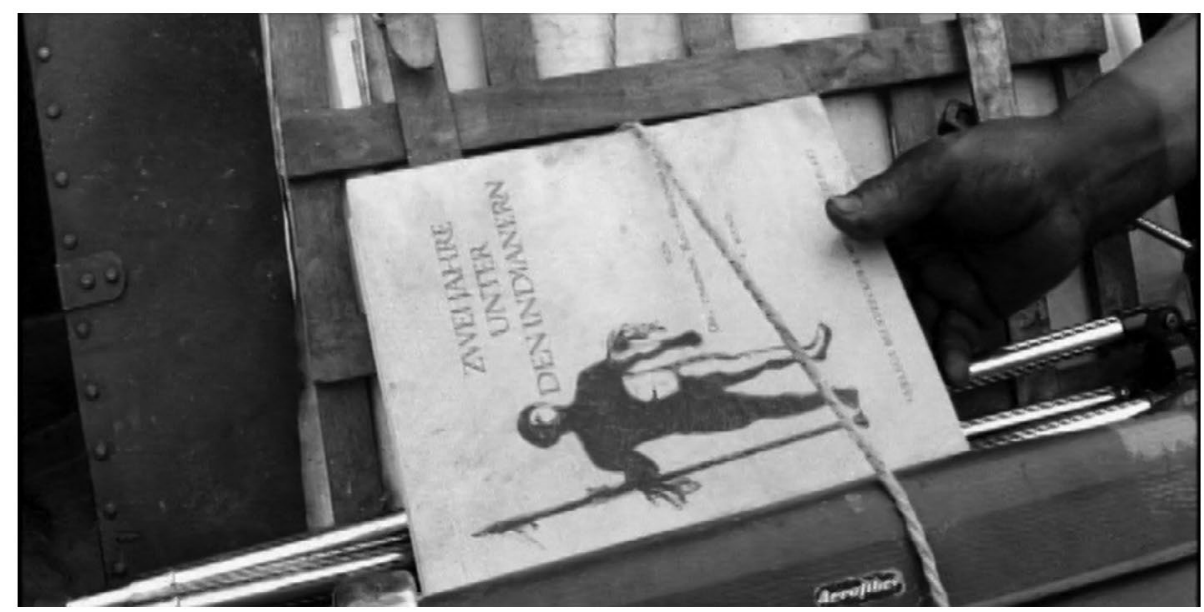

Figura 1. Karamakate toma en sus manos el libro Dos años entre los indios. Reproducida por cortesía de Ciudad Lunar Producciones.

cual clasifica en mise en abyme del enunciado, del texto, de la enunciación, del código y trascendental, pero admite que ninguna mise en abyme es pura y suelen aparecer combinadas $(1989,107)$. Aunque el libro de Koch-Grünberg en El abrazo no se adhiere rigurosamente a la definición de mise en abyme en tanto que no es una duplicación de la totalidad de la obra en la que está contenida, sí es un documento 'enclosed within a work that shows a similarity with the work that contains it' (Dällenbach 1989, 8), que cae dentro de las categorías de mise en abyme del enunciado - pues es an intertextual résumé or quotation of the content of a work' (35) - y de mise en abyme del código (o mise en abyme metatextual) pues ejemplifica la teoría estética del filme y opera como metáfora de la ficción (98). La inestabilidad entre lo real y lo ficticio lograda por la presencia del espejo dentro del relato se exacerba al insertar a su protagonista ficticio - Karamakate - en un texto científico real.

$\mathrm{Al}$ desvanecer las líneas que separan el discurso científico e histórico de la ficción $E l$ abrazo muestra que todo discurso es una representación, una construcción. Como explica Patricia Waugh en su estudio sobre la metaficción, las obras que de manera autoconsciente llaman la atención a su condición de artefacto indagan acerca de la relación entre la ficción y la realidad, y en este proceso exploran la posibilidad de que el mundo real sea ficticio $(2013,2)$. En el caso particular de metaficciones que incorporan personajes reales o eventos históricos Waugh dice que estas obras exponen no solamente la ilusión de la ficción, sino también cuánto hay de ficción en la historia, porque aunque la historia es una realidad material, su existencia está confinada a una construcción textual (106). A este tipo de metaficción Linda Hutcheon le da el nombre de metaficción historiográfica, que ella define como aquellas novelas 'which are both intensely self-reflexive and yet paradoxically also lay claim to historical events and personages' $(2003,5)$. Hutcheon argumenta que la metaficción historiográfica 'always asserts that its world is both resolutely fictive and yet undeniably historical, and that what both realms share is their constitution in and as discourse' (142).

Tomando en cuenta lo anterior cabe entonces preguntarse, ¿por qué el empeño de esta película en mostrar de manera tan patente su sustento histórico, sus lazos con documentos y testimonios de la realidad, para luego exponer lo que hay en esta realidad de ilusorio, 
de fabricación creativa? Con su exploración de la tenue frontera entre historia y ficción $E l$ abrazo desarma la autoridad histórica de los documentos que la inspiraron al ponerlos en diálogo con la ficción, y desde este lugar corrige estos documentos utilizándolos en una versión alternativa sobre el Amazonas y su gente. Esta nueva versión acoge discursos y voces antes ignorados y se adhiere a una ética ambiental que, de acuerdo con la definición de Deane W. Curtin, entiende la justicia social, la justicia ambiental y la justicia económica como componentes inseparables de un todo $(2005,7)$.

Con este propósito en mente, la película se nos presenta como un documento heterogéneo, construido a partir de varias voces y textos, hecho que se comprueba en el entramado intertextual del filme tanto a nivel formal como en su argumento. La imagen frecuente de los personajes en poder de libros y cuadernos, escribiendo y transcribiendo otros textos, son recursos autoconscientes que enfatizan la importancia de la escritura en la película, de una escritura integradora y participativa. Es revelador que en El abrazo los indígenas y los exploradores se leen unos a otros y transcriben por igual los escritos del otro utilizando sus signos: así como Schultes y Theo reproducen en sus cuadernos de apuntes los petroglifos que vemos a la orilla del río, Manduca es el escribano de Theo, quien le dicta en alemán las cartas a su esposa (Figura 2). Es también significativo que el libro de Theo se publica gracias a las gestiones de Manduca, haciendo de la difusión del conocimiento un trabajo colectivo. Incluso la historia oral es una labor compartida; cuando Karamakate olvida cómo preparar el mambe, Schultes lo prepara para él, y más tarde el científico americano le sirve de guía en su viaje en busca de la Yakruna porque Karamakate ha olvidado el camino.

La frase 'el conocimiento es de todos' con la que Karamakate reprende a Theo cuando éste se resiste a regalarle su brújula a los indígenas es la idea central de la película que pone énfasis en la transmisión del conocimiento como un ejercicio comunitario y que se construye a sí misma bajo esta premisa. Sin despojarse totalmente de una perspectiva eurocéntrica - por ejemplo, Jacques Toulemonde reconoce en una entrevista de Camila Builes para el diario El Espectador que el guion fue adecuado a las expectativas de un público 'occidental' (Builes 2016) - el filme se presenta como un ejercicio de re-escritura que busca

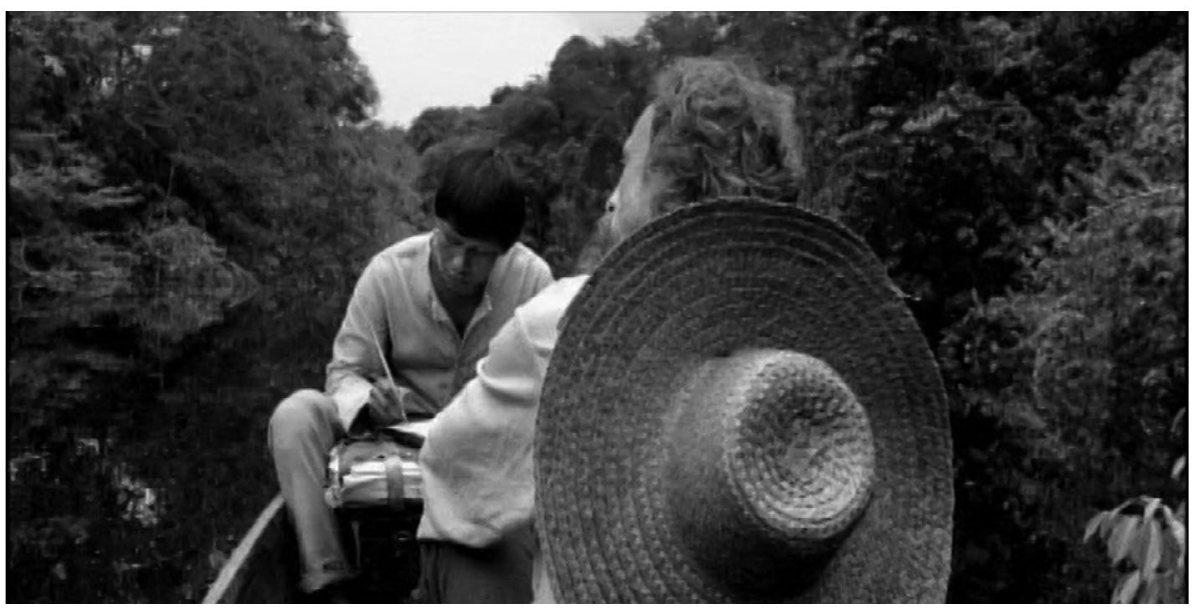

Figura 2. Manduca escribe las cartas de Theo a su esposa. Reproducida por cortesía de Ciudad Lunar Producciones. 
reparar la parcialidad de los textos científicos que la inspiraron. Ya no es el hombre blanco escribiendo sobre el indígena quien pasivamente acepta su papel de objeto de estudio; en el filme de Guerra la escritura surge de un encuentro y este encuentro produce un intercambio cuyo resultado es la descolonización del conocimiento, utilizando el término de Walter Mignolo (2006). La descolonización, como explica Mignolo, implica desprenderse de la matriz colonial del conocimiento y del saber con 'un giro a un paradigma-otro ... [que] es diverso, pluriversal' (17). En la ficción de Guerra este paradigma-otro se da al alterar la naturaleza eurocéntrica de los escritos científicos mediante la inserción de las comunidades indígenas como participantes activos en la producción de conocimiento y en su transmisión mediante la escritura.

En su intención de erigirse como un documento incluyente y heterogéneo sobre el Amazonas El abrazo incorpora también la 'voz' de la naturaleza en su elaboración, revelando con ello la orientación ecológica del filme. La naturaleza, en particular el río, participa en el proyecto colectivo de narrar por medio de las tomas de sus aguas ondulantes que conectan los dos tiempos de la historia. Adicionalmente la perspectiva del río se plasma en aquellas tomas que, desde un ángulo contrapicado, observan la acción desde el agua. Un ejemplo de esto ocurre al principio de la película, que comienza con la imagen y los sonidos del río en movimiento. Segundos después la cámara recorre a Karamakate de abajo hacia arriba, mostrando primero los pies hasta llegar al rostro. En un principio pareciera que la cámara registra la perspectiva de una persona o un animal que observa al protagonista desde el agua, pero no hay tal persona, sino que es el río mismo el que examina a Karamakate. La película personifica al río al conferirle la función de narrar mediante la orientación de la cámara que adopta su perspectiva y la labor de editar la historia a través de tomas del agua que empalman un viaje con el otro. Igualmente, Jacques Toulemonde explica que el río 'con su movimiento, con su sonido, con su fluir' informó la elaboración del guion que busca mostrar 'a todos los personajes en un encuentro constante de conocimiento [...] Los diálogos de la película tienen que ver con el sentir del río' (Builes 2016). De esta manera la impronta ecológica en El abrazo está presente en la participación de la naturaleza, no como telón de fondo, sino como un actor central en la historia.

La conciencia ecológica del filme también se manifiesta en la representación visual de la naturaleza que modifica nuestra percepción del mundo natural y de su relación con los seres humanos. En varias tomas, la puesta en escena y el tratamiento fotográfico hacen que las siluetas de los protagonistas se pierdan entre la maraña selvática, siendo difícil para el espectador distinguirlos. La espesura vegetal en blanco y negro desdibuja a los seres humanos y los vuelve casi invisibles (Figura 3). En ocasiones la vegetación oscurece la pantalla y devora todo a su alrededor, incluso la gente, reduciendo su protagonismo y cuestionando así el paradigma antropocentrista. La inmensidad de la naturaleza también toma forma en aquellas escenas en las que el río, al ocupar la mayoría del cuadro, empequeñece a las personas que lo navegan. Estas escenas se adhieren a la ética de la tierra de Aldo Leopold que 'changes the role of Homo Sapiens from conqueror of the land community to plain member and citizen of it' $(1989,204)$.

Otra manifestación de la conciencia ecológica en la película se encuentra en la escasez de tomas panorámicas, que puede interpretarse como un rechazo a la representación del poder colonial manifiesto en este tipo de imágenes, a las que Mary Louise Pratt ha llamado 'monarch-of all-I survey scene' (2007, 197). Como explica Pratt, en las narrativas de viajes los exploradores y colonizadores observan el paisaje a sus pies desde puntos de observación 


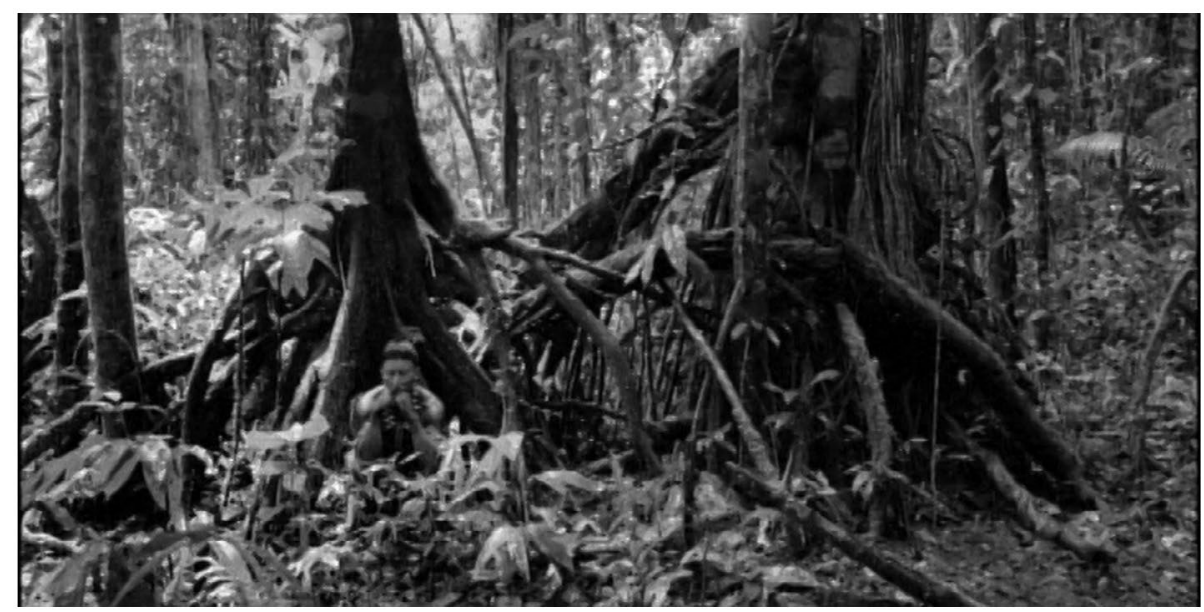

Figura 3. La figura de Karamakate se pierde dentro de la espesura selvática. Reproducida por cortesía de Ciudad Lunar Producciones.

privilegiados, y con esta mirada desde lo alto establecen una relación de dominación del que mira hacia lo mirado (200). El abrazo rechaza esta fantasía de poder sobre la naturaleza y la tierra al evitar las tomas panorámicas del paisaje desde arriba, y de manera aún más reveladora, al preferir las tomas desde abajo, con frecuencia desde el nivel del agua, con el objetivo de replantear la relación entre el ser humano y la naturaleza donde la segunda no está subordinada al primero. La excepción es cerca al final de la película cuando una secuencia de tomas panorámicas muestra el viaje alucinado de Schultes bajo los efectos de la Yakruna. Aquí el cambio de angulación de la cámara y de perspectiva cumple el propósito de recrear el vuelo del viaje espiritual que transporta a Schultes a lugares desconocidos. Es, además, una manera de marcar un contraste - como lo es el uso del color en las escenas que muestran la alucinación - que subraya la adquisición del conocimiento con el uso de la planta medicinal.

En su interés de cuestionar no solamente nuestras actitudes hacia la naturaleza sino cómo esas actitudes permean el plano discursivo, El abrazo se vale de la identidad estética del documento fotográfico para recordarle al espectador que la imagen del mundo natural que ve es en realidad una imagen fabricada, un documento. De esta forma El abrazo cumple con una de las funciones que Scott MacDonald atribuye al ecocinema de avant garde, que es la de volver a entrenar nuestra percepción de la naturaleza al invitarnos a abordar su representación de una manera diferente $(2004,109)$ incluso reconociendo que se trata de una representación. Así la agenda ecológica de la película busca, además de darle un papel primordial a la naturaleza en la narración del Amazonas, urgir al espectador a replantear la relación del ser humano y el mundo natural tanto en el plano real como en el plano discursivo.

Además de avanzar una agenda ecológica a través de estrategias formales, el argumento de El abrazo presenta un mensaje explícito de conservación. Una de las instancias en las que este mensaje se expresa de manera directa es en la escena en la que Karamakate dialoga con los niños indígenas que viven en la misión de los capuchinos y los educa acerca de la destrucción de la naturaleza a manos del hombre blanco. Frente a la mirada alarmada de los 
niños, Karamakate les explica que el hombre blanco les da comida, pero algún día acabará con los recursos naturales. Luego les advierte que 'cada planta, cada árbol, cada flor está llena de sabiduría' y que ellos no deben olvidar quiénes son y de dónde vienen (Elabrazo de la serpiente 2015). La importancia de la naturaleza y su preservación también se manifiesta en la frustración del protagonista debido a que su relación cercana con la naturaleza se ha debilitado con los años pues ya no la escucha. Esta preocupación, en boca del sabio indígena, es un llamado de atención a la humanidad entera. Es, también, una confirmación de la ética ecológica que rige el concepto que los indígenas tienen de lo natural - y que la película adopta - donde los seres humanos son miembros de la comunidad de la naturaleza y no sus dueños.

De la misma manera que El abrazo evita imponer una mirada colonizadora sobre el paisaje selvático, también rechaza la mirada imperial sobre el sujeto colonial con tomas que observan a los indígenas desde abajo - como cuando los exploradores enfermos observan a Karamakate buscando su ayuda - o tomas que capturan la figura Karamakate de espaldas replicando su perspectiva (Figura 4). Tanto la subordinación de la cámara a la autoridad del indígena en las primeras tomas como la identificación del espectador con Karamakate en las tomas de espaldas subvierten la impronta colonial de producciones en las que los indígenas figuran como parte del paisaje o como curiosidades que están ahí para ser observadas con extrañeza.

Este tratamiento de la cámara marca un contraste llamativo con la mirada imperial utilizada en producciones anteriores. Lutz P. Koepnick, en su estudio sobre la representación de la selva en Aguirre, The Wrath of God (1972) y Fitzcarraldo (1981) de Werner Herzog, afirma que ambas películas presentan el fracaso de iniciativas coloniales debido a la incapacidad de sus protagonistas de escapar su imaginación occidental (1993, 135). Explica Koepnick que, en el caso particular de Aguirre, Herzog expone el colonialismo como un sistema de percepción fallido que busca mirar al paisaje desde arriba en un acto de apropiación imperial y a los indígenas como 'mirages in motion, as silhouettes and specters that briefly appear along the banks of the river' (140). La derrota de Aguirre está en su ceguera, dice

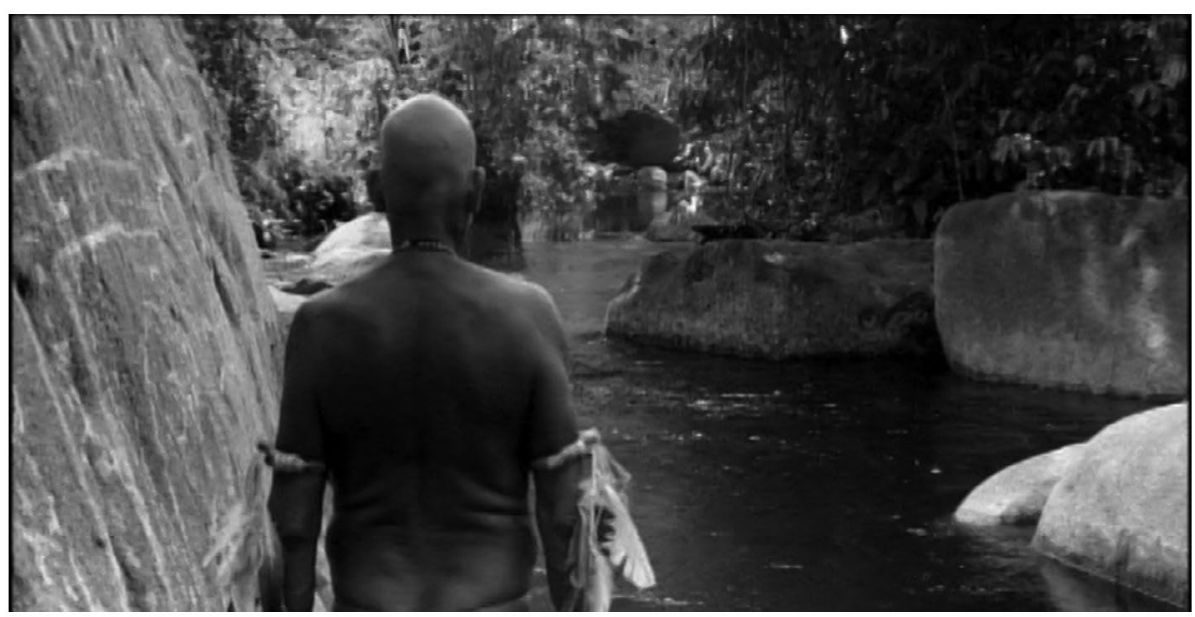

Figura 4. Una de las muchas ocasiones en las que se muestra a Karamakate de espaldas. Reproducida por cortesía de Ciudad Lunar Producciones. 
Koepnick, en las distorsiones de su óptica colonial que en su afán de dominación reducen la complejidad natural de la selva y niegan a las culturas que en ella habitan (141). En El abrazo, la validación de las comunidades amazónicas por medio de su participación activa en la escritura y documentación del Amazonas, sumado a un uso de la cámara que les da un trato respetuoso, certifican su orientación poscolonial.

Como hemos visto, en El abrazo convergen preocupaciones ecológicas y poscoloniales que, al ser abordadas desde una óptica posmoderna, revelan y corrigen la opresión colonial escondida en el discurso hegemónico. Koepnick señala que en Aguirre la escritura y la documentación fracasan en su objetivo de trazar un nuevo orden pues simplemente promueven 'megalomaniac illusions about absolute control and, thus, record nothing other than the evanescence of historical consciousness' $(1993,150)$. En contraste, El abrazo traza un nuevo orden en el que la escritura y la documentación histórica - así como la ficción que estas inspiran - proviene del intercambio de diferentes culturas, de la colaboración de indígenas y exploradores con la participación activa de la naturaleza. El mensaje de la película parece ser que solamente producido de esta manera el discurso puede irradiar conocimiento y despertar conciencias y así cambiar el destino de la región.

Este mensaje se refuerza mediante el aprovechamiento del poder simbólico de la fotografía y de su estrecha cercanía con el cine. Anteriormente se mencionó que las fotografías de Koch-Grünberg que aparecen en el filme actúan como repeticiones en miniatura de partes de la historia contada por la película, de donde puede interpretarse que funcionan como símbolos de la película misma que contienen su mensaje o significado. También se mencionó que la película conecta el desdoblamiento causado por la imagen fotográfica al mito del Chullachaqui. En una reveladora escena Karamakate, al observar su fotografía, le dice a Theo que la foto es su chullachaqui, que todas las personas tienen uno, y que es un doble que está vacío, es decir, que es solamente una imagen, un espectro. Años más tarde, en el viaje de Karamakate con Schultes, una fotografía de Theo suscita una conversación similar que culmina con Karamakate lamentando que en su vejez él mismo se haya convertido en chullachaqui. El protagonista piensa que su identidad se ha reducido a un espectro de lo que era, a una imagen vacía, debido a que ha perdido la memoria, sus conocimientos, sus sueños y su conexión con la naturaleza. Al final de la película presenciamos la redención de Karamakate, cuando él entiende que su misión en la vida es la de dar a conocer su cultura a Schultes y transmitirle, con la ayuda de la Yakruna, sus conocimientos sobre el Amazonas, sus pueblos y su naturaleza. En ese momento Karamakate comprende que solamente mediante la transmisión de sus conocimientos al hombre blanco, éste podrá entender la importancia del Amazonas y de su gente, y así evitar su destrucción. Con esta revelación descubre que ya no es un chullachaqui y que su redención personal es también la de su gente. La transformación de Karamakate, de sentirse como una imagen vacía a saberse un ser completo, se da al contarle al mundo su verdad.

El símbolo del chullachaqui, liado a la fotografía, que a su vez es una duplicación de la película, entraña la misión del filme: contar la historia del Amazonas porque la salvación de la región depende de ello. En una entrevista con Susannah Bragg McCullough para Screenprism Ciro Guerra da soporte a esta interpretación de la película al afirmar que el Chullachaqui es una metáfora de lo que sienten las tribus amazónicas, que temen que su cultura, sus lenguas y tradiciones se estén perdiendo (2016). En la misma entrevista Guerra afirma que el propósito de la película es restaurar el respeto por la cultura amazónica. En un nivel simbólico Ciro Guerra busca transferir a la película la gran transformación de 
Karamakate, de ser un chullachaqui - una imagen fotográfica, espectral y vacía - a ser una fuente de conocimiento sobre la región y la cultura de sus comunidades. Por medio de sus variadas estrategias autoreflexivas El abrazo propone que la transmisión justa y ética de este conocimiento solamente puede darse si a todos - indígenas, exploradores y naturaleza - se les invita a participar en la construcción de la historia. Porque en efecto la frase de Karamakate de que 'el conocimiento es de todos' no sólo implica que a todos pertenece, sino que todos, también, participan en su producción y transmisión. El abrazo es, de este modo, un nuevo documento que rescata las voces silenciadas en el discurso hegemónico y les da su lugar dentro del inmenso y rico archivo del Amazonas.

\section{Cláusula de divulgación}

El autor no declara ningún conflicto de intereses potencial.

\section{Nota sobre la autora}

Ana María Mutis es instructora en Trinity University en San Antonio, Texas. Sus áreas de investigación incluyen la naturaleza en la ficción latinoamericana contemporánea, la representación de la violencia en la literatura, intersecciones entre espacios y violencia, estudios transatlánticos y la metaficción en la literatura y el cine. Ha escrito artículos sobre narrativa y poesía latinoamericana en revistas académicas como Revista de Crítica Literaria Latinoamericana, Revista Iberoamericana, Revista Canadiense de Estudios Hispánicos y Revista Hispánica Moderna entre otras. Es co-editora del volumen titulado Troubled Waters: Rivers in Latin American Imagination (2013) y co-escribió un capítulo para la History of Colombian Literature, ed. Raymond Williams (2016).

\section{Bibliografía}

Barthes, R. 1993. Camera Lucida: Reflections on Photography. Translated by R. Howard. New ed. London: Vintage Classics.

Berger, J. 1993. The Sense of Sight. 1st Vintage International ed. New York: Vintage.

Bragg McCullough, S. 2016. "Ask the Director: In 'Embrace of the Serpent', What is the Meaning of the Chullachaqui?” ScreenPrism, February 17. Accessed 30 June 2016. http://screenprism.com/ insights/article/in-embrace-of-the-serpent-what-is-the-concept-of-the-chullachaqui

Buell, L. 1996. The Environmental Imagination: Thoreau, Nature Writing, and the Formation of American Culture. Cambridge, MA: Harvard University Press.

Builes, C. 2016. "El guión de El abrazo de la serpiente." El espectador, February 24. Accessed 23 June 2016. http://www.elespectador.com/noticias/cultura/el-guion-de-el-abrazo-de-serpientearticulo-618466

Curtin, D. W. 2005. Environmental Ethics for a Postcolonial World. Lanham: Rowman \& Littlefield.

Dällenbach, L. 1989. The Mirror in the Text. Chicago, IL: University of Chicago Press.

Davis, W. 1996. One River: Explorations and Discoveries in the Amazon Rain Forest. New York: Simon \& Schuster.

Feier, J. 2011. We Never Hunted Buffalo: The Emergence of Native American Cinema. Münster: LIT Verlag.

Gallego, D. 2016. “Embrace of the Serpent.” MovieMaker 23 (117): 18-19.

Gide, A. 2000. Journals: 1889-1913. Translated by Justin O’Brien. Urbana: University of Illinois Press.

Huggan, G., and H. Tiffin. 2015. Postcolonial Ecocriticism: Literature, Animals, Environment. New York: Routledge.

Hutcheon, L. 2003. A Poetics of Postmodernism: History, Theory, Fiction. New York: Routledge. 
Koch-Grünberg, T. (1909-1910) 1995. Dos años entre los indios: viajes por el noroeste brasileño, 1903-1905. Bogotá: Editorial Universidad Nacional de Colombia.

Koepnick, L. P. 1993. "Colonial Forestry: Sylvan Politics in Werner Herzog's Aguirre and Fitzcarraldo." New German Critique: An Interdisciplinary Journal of German Studies 60: 133-159.

Leopold, A. 1989. A Sand County Almanac, and Sketches Here and There. New York: Oxford University Press.

MacDonald, S. 2004. “Toward an Eco-Cinema." ISLE Interdisciplinary Studies in Literature and Environment 11 (2): 107-132. doi:10.1093/isle/11.2.107.

Mignolo, W. 2006. "El desprendimiento: pensamiento crítico y giro descolonial." In Interculturalidad, descolonización del estado y del conocimiento, edited by Catherine Walsh, Álvaro García Linera, and Walter Mignolo, 9-20. Buenos Aires: Ediciones del Signo.

Muredda, A. 2016. "Embrace of the Serpent." Cinema Scope 66: 74-75.

Oppermann, S. 2006. “Theorizing Ecocriticism: Toward a Postmodern Ecocritical Practice." ISLE Interdisciplinary Studies in Literature and Environment 13 (2): 103-128. doi:10.1093/isle/13.2.103.

Pratt, M. L. 2007. Imperial Eyes: Travel Writing and Transculturation. 2nd ed. New York: Routledge. Sontag, S. 1977. On Photography. New York: Farrar, Straus and Giroux.

Waugh, P. 2013. Metafiction. The Theory and Practice of Self-conscious Fiction. New York: Routledge.

\section{Filmografía}

Aguirre, The Wrath of God. 1972. Dirigida por Werner Herzog [DVD]. USA: Anchor Bay Entertainment.

El abrazo de la serpiente. 2015. Dirigida por Ciro Guerra [DVD]. Colombia: Oscilloscope Pictures. Fitzcarraldo. 1981. Dirigida por Werner Herzog [DVD]. USA: Anchor Bay Entertainment. 